\title{
Advances in Microwave-Assisted Production of Reduced Graphene Oxide
}

\author{
Xinxin Xie ${ }^{1,2}$, Yanping Zhou ${ }^{1,2 *}$ and Kama Huang ${ }^{1,2}$ \\ ${ }^{1}$ College of Electronics and Information Engineering, Sichuan University, Chengdu, China, ${ }^{2}$ Key Laboratory of Wireless \\ Power Transmission of Ministry of Education, Sichuan University, Chengdu, China
}

Efficient reduction of graphene oxide to obtain high-quality graphene nanosheets is desirable for energy storage, catalysis, electronics and environmental remediation. In this brief review, we mainly focus on the microwave-assisted production of reduced graphene oxide in three categories: (1) microwave-assisted chemical reduction of graphene oxide; (2) microwave-assisted thermal reduction of graphene oxide; (3) microwave-assisted simultaneous thermal exfoliation \& thermal reduction of graphite oxide. We also summarize common techniques for characterizing reduction efficiency and quality of as-obtained rGO.

Keywords: microwave-assisted synthesis, reduced graphene oxide, chemical reduction, thermal reduction, exfoliation of graphite oxide

OPEN ACCESS

Edited by:

Wenping Sun,

University of Wollongong, Australia

Reviewed by:

Jiantie $X u$

South China University of

Technology, China

Chao Wu,

University of Wollongong, Australia

*Correspondence:

Yanping Zhou

ypzhou11@scu.edu.cn

Specialty section:

This article was submitted to

Electrochemistry,

a section of the journal

Frontiers in Chemistry

Received: 21 February 2019

Accepted: 30 April 2019

Published: 04 June 2019

Citation:

Xie X, Zhou Y and Huang K (2019) Advances in Microwave-Assisted Production of Reduced Graphene

Oxide. Front. Chem. 7:355.

doi: 10.3389/fchem.2019.00355

\section{INTRODUCTION}

Graphene is a two-dimensional sheet of sp2-hybridized carbon. Owing to its theoretically high mechanical strength $(1,060 \mathrm{GPa})$, thermal conductivity $\left(\sim 5,000 \mathrm{~W} \mathrm{~m}^{-1} \mathrm{~K}^{-1}\right)$, electron mobility $\left(2 \times 105 \mathrm{~cm}^{2} \mathrm{~V}^{-1} \mathrm{~s}^{-1}\right)$, Young's modulus $(\sim 1 \mathrm{TPa})$, surface area $\left(2,630 \mathrm{~m}^{2} \mathrm{~g}^{-1}\right)$, electrical conductivity $\left(\sim 2,000 \mathrm{~S} \mathrm{~m}^{-1}\right)$, and extraordinary optical properties, graphene has been attracting increasing application in various areas including energy storage [like fuel cells (Li et al., 2012; Hur and Park, 2013; Li and Wu, 2015), batteries (Li et al., 2015; Bak et al., 2016; Kaur et al., 2018), supercapacitors (Le et al., 2011; Akhavan, 2015)], sensors (Shao et al., 2010; Wang and Arash, 2014; Chatterjee et al., 2015), catalysis (Han et al., 2017; Hu et al., 2017), electronics (like liquid crystal displays (Novoselov et al., 2005; Lin et al., 2015; Basu et al., 2016; Narayan et al., 2016), touch panels (Das and Prusty, 2013; Liu et al., 2014; Katkov and Osipov, 2017), electromagnetic interference shielding (Eswaraiah et al., 2011; Thomassin et al., 2013; Song et al., 2014; Cao et al., 2015), environmental remediation (Bi et al., 2012; Qin and Brosseau, 2012; Chabot et al., 2014), and so on. Clearly, there will be an increasing demand for high quality graphene.

Currently, reduction of graphene oxide or simultaneous exfoliation and reduction of graphite oxide are regarded to be most promising for large scale production of chemically derived graphene, which can be defined as reduced graphene oxide (rGO). In general, there are mainly two strategies used for graphene oxide reduction: chemical reduction and thermal reduction, both of which are facing certain challenges. In chemical reduction methods, the reduction efficiency is unsatisfactory, requiring long treating time and yielding rGO with oxygen content usually higher than $15 \%$ (Stankovich et al., 2007; Shao et al., 2010; Mattevi et al., 2011; Park et al., 2011b; Xiao et al., 2013; Zhang et al., 2013; Wen et al., 2014). In thermal reduction process, long-time high-temperature treatment is not only energy consuming but also results in fragmentation of graphene and lots of structural defects (Jones et al., 2002; Chen and Yan, 2010; Chen et al., 2010; Gao et al., 2010; Lin et al., 2010; Zhu et al., 2010b; Zhang et al., 2011). 
Microwave heats materials directly through dielectric loss rather than heat convection as in the conventional heating method, and hence can enable fast heating and selective heating. It is regarded to be promising in shortening the reaction time and yielding hot spots with extraordinary high temperature (Thostenson and Chou, 1999; Kappe, 2004; Tompsett et al., 2006; Schwenke et al., 2015). As such, material scientists have devoted much effort to explore the potential application of microwave in overcoming the current problems and facilitating the fabrication of high-quality rGO in large-scale. To this end, we present an up-to-date critical survey of literature relevant to MW-assisted production of rGO. This brief review is organized as follows. First, techniques for characterizing quality of asobtained rGO are discussed. Next, we provide a comprehensive summary of microwave-assisted chemical reduction of graphene oxide, microwave-assisted thermal reduction of graphene oxide, and microwave-assisted simultaneous thermal exfoliation and reduction of graphite oxide, respectively.

\section{TECHNIQUES FOR CHARACTERIZING QUALITY OF RGO}

Generally, X-ray diffraction, X-ray photoelectron spectroscopy, Raman spectroscopy, electrical conductivity, thermal gravity analysis are common techniques used for characterizing reducing efficiency and quality of rGO.

\section{X-Ray Diffraction}

The X-ray diffraction (XRD) pattern of graphene/graphite oxide usually shows a characteristic diffraction peak at $2 \theta=10.9^{\circ}$ with the corresponding d-spacing of $0.81 \mathrm{~nm}$ (Stobinski et al., 2014; Strankowski et al., 2016), due to insertion of hydroxyl and epoxy groups between the carbon sheets. After reduction, two types of XRD spectra may be obtained: (1) The XRD pattern with no peaks, suggesting the complete reduction and the formation of single-layered rGO (Hassan et al., 2009). (2) The XRD pattern showing a broad peak around $26.5^{\circ}$ (Zedan et al., 2010; Liu et al., 2011; Park et al., 2011b; Wang et al., 2011; Pokharel et al., 2014). Since the oxygen-containing functional groups could lead to a reduction in crystallinity, the higher the broad peak's intensity is, the higher the crystallinity degree is, and the better graphene/graphite oxide is reduced.

\section{X-Ray Photoelectron Spectroscopy}

$\mathrm{X}$-ray photoelectron spectroscopy (XPS) could help to obtain qualitative and quantitative analysis results of the content of oxygenated groups. For example, the carbon/oxygen atomic ratio ( $\mathrm{C} / \mathrm{O}$ ratio) could be evaluated from the areas of $\mathrm{C} 1 \mathrm{~s}$ and $\mathrm{O} 1 \mathrm{~s}$ peaks and the atomic sensitivity factor. Usually, the $\mathrm{C} / \mathrm{O}$ ratio of graphene oxide is 2.2-2.7 (Stankovich et al., 2007; Chen et al., 2010; Park et al., 2011a; Li et al., 2013; Wen et al., 2014; Han et al., 2015), attributed to the abundant oxygen-containing functional groups introduced during oxidation of graphite. Further, the $\mathrm{C} 1 \mathrm{~s}$ peak can be decomposed into three peaks: $\mathrm{C}=\mathrm{C}(284.7 \mathrm{eV}), \mathrm{C}-$ $\mathrm{O}(286.9 \mathrm{eV}), \mathrm{C}=\mathrm{O}(287.77 \mathrm{eV})$ (Zhao et al., 2014), through the areas of which existing statuses of oxygen could be analyzed in a quantitative manner.

\section{Raman Spectroscopy}

The D band around $1,350 \mathrm{~cm}^{-1}$ in Raman spectra could reflect the disorder degree of the crystal structure of carbon while the $G$ band around $1,580 \mathrm{~cm}^{-1}$ represents a first-order scattering $\mathrm{E}_{2 \mathrm{~g}}$ vibration mode for characterizing the $\mathrm{sp} 2$ bond structure of carbon. $\mathrm{I}_{\mathrm{D}} / \mathrm{I}_{\mathrm{G}}$ is the ratio of $\mathrm{D}$ band intensity to $\mathrm{G}$ band intensity, which could be used to evaluate the quality of the graphene structure. The higher $\mathrm{I}_{\mathrm{D}} / \mathrm{I}_{\mathrm{G}}$ is, the more defects of $\mathrm{C}$ atom crystal there are. In the Raman spectrum of graphene, the D-band peak could not be observed. However, the $\mathrm{I}_{\mathrm{D}} / \mathrm{I}_{\mathrm{G}}$ of graphene oxide could be as high as $\sim 0.8-1$ (Chen et al., 2010; Lin et al., 2010; Liu et al., 2011; Park et al., 2011a; Zhao et al., 2014). Besides, the number of rGO layers can be estimated by observing the shape and position of the 2D peak in Raman spectra which is the second-order two-phonon process. For example, single-layer graphene exhibits a single, sharp 2D band located below 2,700 $\mathrm{cm}^{-1}$, while bilayer sheets have a broader 2D peak around 2,700 $\mathrm{cm}^{-1}$, and sheets more than five layers have a broad 2D peak above 2,700 $\mathrm{cm}^{-1}$ (Hassan et al., 2009).

\section{Electrical Conductivity}

Though the conductivity of graphene is as high as $1 \times 10^{8} \mathrm{~S} \mathrm{~m}^{-1}$, that of graphene oxide is about 0.02-0.07 S m $\mathrm{m}^{-1}$ (Li et al., 2010; Zhu et al., 2010a; Park et al., 2011a) due to the existence of oxygen-containing functional groups which disrupted sp2 bonding networks. During the reduction process, electrical conductivity can be recovered by restoring the p-network as oxygen-containing groups leave, leading to a conductivity improvement by 3-6 orders of magnitude (Chen et al., 2010; Dreyer et al., 2010; Zhao et al., 2014; Han et al., 2015). Therefore, the restoration degree of conductivity can indirectly reflect the reduction degree and quality of rGO.

\section{Thermal Gravity Analysis}

Graphene/Graphite has a very good thermal stability even when being heated up to $900^{\circ} \mathrm{C}$ (Bastiurea et al., 2015). For graphene oxide, it starts to have significant mass loss from $\sim 200^{\circ} \mathrm{C}$ due to the decomposition of labile oxygen functional groups leads to poor thermal stability (Hassan et al., 2009; Chen et al., 2010; Zhu et al., 2010a; Gannavarapu et al., 2018). Therefore, the removal of oxygen-containing functional groups can help to restore its thermal stability. The significant mass loss temperature of rGO usually happens around $500-800^{\circ} \mathrm{C}$, depending on the reduction degree of rGO.

\section{MICROWAVE-ASSISTED PRODUCTION OF REDUCED GRAPHENE OXIDE}

Methods for producing rGO could generally be categorized into chemical reduction of graphene oxide, thermal reduction of graphene oxide, and simultaneous thermal exfoliation and reduction of graphite oxide. Here, we would also discuss microwave-assisted production of rGO in these three categories separately. 


\section{Microwave-Assisted Chemical Reduction of Graphene Oxide}

Strong reducing reagents have been widely used to reduce graphene oxide. However, the reduction process is very slow. For example, hydrazine hydrate enabled reduction of graphene oxide in the oil bath for $12 \mathrm{~h}$ and $24 \mathrm{~h}$ resulted in a C/O ratio about 5 (Park et al., 2011b) and 10.3 (Stankovich et al., 2007), respectively. Microwave irradiation was found to be capable of accelerating the reducing rate significantly. For example, Hassan et al. (2009) reported microwave assisted hydrazine hydrate reduction of graphene oxide. After microwave treatment for $2 \times 30 \mathrm{~s}$ (on for $10 \mathrm{~s}$, off and stirring for $20 \mathrm{~s}$ ), the $\mathrm{I}_{\mathrm{D}} / \mathrm{I}_{\mathrm{G}}$ in Raman spectra was $0.1-0.12$, indicating a high reduction degree even after such a short treating time This was confirmed by the improved thermal stability, showing no significant mass loss up to $750^{\circ} \mathrm{C}$. Elazab et al. (2015) obtained $\mathrm{Pd} / \mathrm{Fe}_{3} \mathrm{O}_{4}$ nanoparticles supported on graphene nanosheets by a one-pot microwave heating with the existence of hydrazine hydrate. After microwave irradiation for $2 \mathrm{~min}$, the $\mathrm{C} / \mathrm{O}$ of $\mathrm{rGO}$ was determined to be 8.1. Kumar et al. (2015) reported microwave-enhanced chemical reduction of graphene oxide using $\mathrm{HI} / \mathrm{CH}_{3} \mathrm{COOH}$ as reducing reagent. They found the effect of $4 \mathrm{~h}$ microwave irradiation was comparable to $48 \mathrm{~h}$ conventional reaction process.

Since strong reducing regents are very much expensive and hazardous, organic solvents have also been explored to reduce graphene oxide. Zedan et al. (2010) reported MW-assisted reduction of graphene oxide in dimethyl sulfoxide (DMSO), a solvent with high microwave absorbing capability. The reduction degree of the sample prepared from 2 min MW irradiation at $1,200 \mathrm{~W}$ is even much higher than that of the sample derived from $7 \mathrm{~h}$ conventional heating treatment, as evidenced by XRD results of both samples shown in Figures 1a,b. After 2 min of MW irradiation in DMSO, the color of the product changed to black (Figure 1c), and the XRD pattern showed no characteristic peak $\left(10.9^{\circ}\right)$ of GO, indicating that most of the $\mathrm{GO}$ has been converted into rGO. In contrast, under conventional heating at $180^{\circ} \mathrm{C}$, an apparent peak located at $10.9^{\circ}$ was found even after $7 \mathrm{~h}$ treatment. It was not until 12th $\mathrm{h}$ that the GO was completely reduced, as can be seen from the disappearance of the peak at $10.9^{\circ}$ in the XRD pattern and the color change of the sample to black (Figure 1d). Chen et al. (2010) reported the microwave-enhanced chemical reduction of graphene oxide to $\mathrm{rGO}$ in a mixed solution of $\mathrm{N}, \mathrm{N}$-dimethylacetamide (DMAc) and water without any additional reductant under nitrogen purge. The XRD pattern of the graphene oxide showed a wide peak, indicating the damage of the regular crystalline pattern of graphite during the oxidation. After microwave treatment for $2 \mathrm{~min} \times 5$ times $(2.45 \mathrm{GHz}$, $800 \mathrm{~W}$ ), no peak was observed indicating microwave-assisted formation of single-layered graphene. XPS results showed that $\mathrm{C} / \mathrm{O}$ ratio changed from 2.09 to 5.46 , confirming that the removal of oxygen containing groups happened. However, the $\mathrm{I}_{\mathrm{D}} / \mathrm{I}_{\mathrm{G}}$ in Raman spectra changed from 0.95 to 0.96 , suggesting that the reduction led to an increase of aromatic domains of smaller overall size in graphene. Similarly, Liu et al. (2011) also reported an increase of the product's $\mathrm{I}_{\mathrm{D}} / \mathrm{I}_{\mathrm{G}}$ in Raman spectra from 0.80 to 0.94 after being treated by microwave at $750 \mathrm{~W}$ for $2 \mathrm{~min}$ in $\mathrm{N}$, $\mathrm{N}$-dimethylacetamide (DMF) solution. Zhao et al. (2014) applied
DMF to reduce graphite oxide under microwave irradiation at $100 \mathrm{~W}$ for $30 \mathrm{~min}$. The XPS results showed that $\mathrm{C} / \mathrm{O}$ ratio rose from 2.13 to 6.13 while Raman results showed that $\mathrm{I}_{\mathrm{D}} / \mathrm{I}_{\mathrm{G}}$ remained almost unchanged.

The characteristics of the as-obtained rGO products derived from different microwave-assisted chemical reduction methods are summarized and listed in Table $\mathbf{1}$. Since microwave heat rapidly, microwave-assisted rate enhancement in chemical reduction of graphene oxide has been widely observed, with most of the reaction time $<10 \mathrm{~min}$. However, as in the conventional heating method, the as-obtained rGO is still unsatisfactory, facing the same problem of containing a high oxygen content and a high $I_{D} / I_{G}$ value when organic solvent was used as the reducing reagent. Microwave-enhanced quality of chemically reduced rGO is yet to be explored. Also, since the type and amount of reducing agents were different in different work, it is difficult to draw a conclusion regarding the effect of microwave power and treating time here.

\section{Microwave-Assisted Thermal Reduction of Graphene Oxide}

In conventional thermal reduction process, long-time hightemperature treatment in a protecting atmosphere (e.g., $\mathrm{N}_{2} / \mathrm{Ar}$ ) is usually required, which is not only very energy consuming but also leads to the formation of defects in the graphene basal plane because of the evolution of the oxygen functional groups during reduction, like nanoscopic holes brought by carbon loss as $\mathrm{CO}$ or $\mathrm{CO}_{2}$ and Stone-Wales types of defects lead by rearrangement of carbon atoms in the graphene basal plane. Besides, the reducing efficiency is always suppressed by the highly stable ether and carbonyl groups formed between the oxygen functional groups.

In 2010, Li et al. (2010) for the first time reported a microwaveassisted thermal reduction of graphene oxide. Specifically, they made the graphene oxide into a free-standing film via filtration membrane, and then treated it with a microwave irradiation with a frequency of $6.425 \pm 1.150 \mathrm{GHz}$ at a power of $500 \mathrm{~W}$ without purging any inert gas. As shown in Figures 2a,b, after $1 \mathrm{~s}$ irradiation, the temperature rose only a little and no distinct difference were found in the electrical properties and the Raman spectra of the sample. However, after $2 \mathrm{~s}$ irradiation, the surface temperature of the graphene oxide film ramped up to $400^{\circ} \mathrm{C}$ and the conductivity of the graphene oxide film increased from 0.07 to $1 \times 10^{4} \mathrm{~S} \mathrm{~m}^{-1}$; the $\mathrm{I}_{\mathrm{D}} / \mathrm{I}_{\mathrm{G}}$ in Raman spectra decreased from 1 to 0.3 ; the mass loss temperature increased from 181 to $668^{\circ} \mathrm{C}$ (Figure 2c). In addition, they found that in the MW treatment process, fierce degassing and a high gas pressure inside the graphene oxide was generated, which was beneficial for exfoliating the graphene oxide into thinner graphene sheets. Afterwards, they also applied a household MW oven (with a frequency of $2.45 \mathrm{GHz}$ and a power of $1,000 \mathrm{~W})$ to treat the free-standing graphene oxide film. They found that there was an optimal irradiation time of $8 \mathrm{~min}$ as evidenced by Raman spectra (Figure 2d) and TGA results (Figure 2e). Longer treatment time (e.g., $10 \mathrm{~min}$ ) caused lower mass loss temperature (from $700^{\circ} \mathrm{C}$ to around $800^{\circ} \mathrm{C}$ ), which 

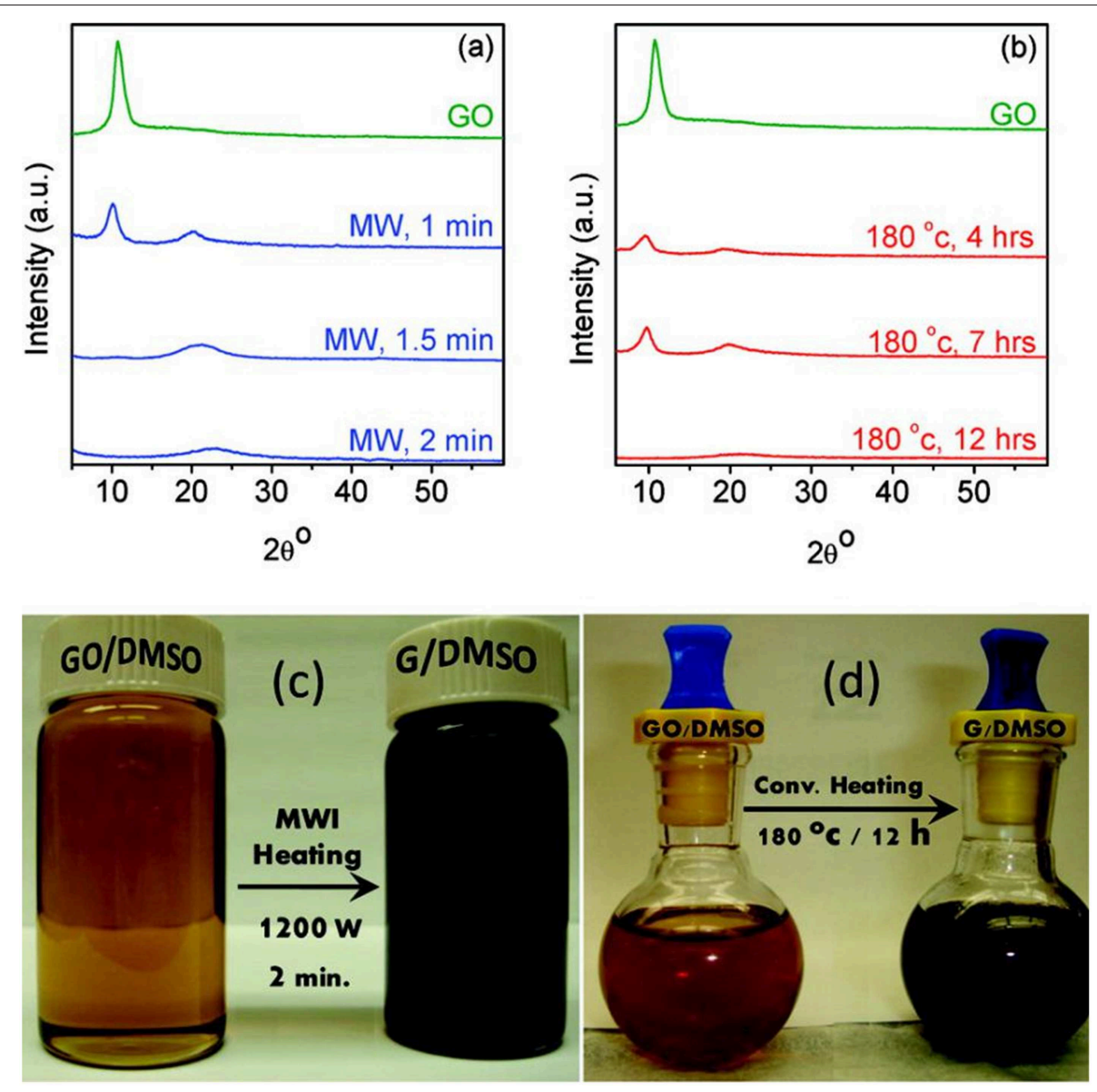

FIGURE 1 | (a) XRD pattern of graphene oxide after microwave reduction for 1, 1.5, and 2 min. (b) thermal reduction after 4, 7 , and $12 \mathrm{~h}$. Digital camera images of graphene oxide and graphene colloidal suspensions in DMSO for (c) microwave and (d) thermal syntheses. [Reprinted with permission from Zedan et al. (2010), copyright 2010 American Chemical Society].

could possibly be attributed to the oxidation by air when there was no protecting gas.

Considering the weak microwave absorption of graphene at low frequency, while $2.45 \mathrm{GHz}$ and $915 \mathrm{MHz}$ are most commonly used in industry, Voiry et al. (2016) introduced a conventional mild annealing process before the microwave irradiation process. Firstly, the single-layered graphene oxide solution was slowly injected into an aqueous solution that contained $1 \mathrm{wt} \%$ $\mathrm{CaCl}_{2}$, which helps to coagulate $\mathrm{GO}$ nanosheets and promote solidification via bridging with the oxygen-containing groups from two GO nanosheets, yielding uniform and continuous gelatinous GO. The coagulated graphene oxide was then washed with DI water and dried, which was subsequently annealed at $300^{\circ} \mathrm{C}$ for $1 \mathrm{~h}$ under Argon to yield mildly reduced graphene oxide that was capable of absorbing microwaves at $2.45 \mathrm{GHz}$ effectively. After 1-2 s long microwave irradiation in microwave oven at $1,000 \mathrm{~W}$ in argon, the efficient absorption of microwave led to rapid heating of the mildly reduced GO and consequently brought large arcing as shown in Figure 3a, causing desorption of oxygen functional groups and reordering of the graphene basal plane. As such, the as-obtained rGO exhibited pristine CVD graphene-like features in the Raman spectrum showing sharp $\mathrm{G}$ an $2 \mathrm{D}$ peaks and a nearly absence of $\mathrm{D}$ peak. In contrast, the rGO derived from conventional thermal reduction remains highly disordered, as indicated by the presence of an intense and broad disorder $\mathrm{D}$ band and the absence of the 2D band in the Raman spectra (Figure $3 \mathbf{b}$ ). The XPS results were well in agreement with the Raman results. Owning to the large arcing which may possibly resulted in an extremely high temperature, the oxygen content of the MWrGO was about $4 \%$, lower than that theoretically predicted for rGO after annealing at $1,500 \mathrm{~K}$ (15-25\%). Aberration corrected HR-TEM (Figure 3c) also suggested a highly ordered structure, which suggests that there is some reorganization of the carbon bonding during microwave reduction, along with removal of oxygen facilitated by achieving exceptionally high temperatures.

Jiang et al. (2018) further modified Voiry's strategy and developed a triggered microwave-assisted reduction of graphene oxide. In their work, $1 \mathrm{wt} \% \mathrm{CaCl}_{2}$ aqueous solution was used to treat one side of the filter paper while graphene oxide was dropped onto the other side of the filter paper. Subsequently, 
TABLE 1 | Characteristics of rGO products derived from different microwave-assisted chemical reduction.

\begin{tabular}{|c|c|c|c|c|c|c|c|c|c|c|c|}
\hline \multicolumn{6}{|c|}{ Experiment conditions } & \multicolumn{5}{|c|}{ Results } & \multirow[t]{2}{*}{ References } \\
\hline & Frequency & $\begin{array}{l}\text { MW } \\
\text { power }\end{array}$ & $\begin{array}{l}\text { MW } \\
\text { time }\end{array}$ & Atmosphere & $\begin{array}{l}\text { Reducing } \\
\text { agent }\end{array}$ & $\begin{array}{l}\text { XRD } \\
\text { (Peak } \\
\text { location) }\end{array}$ & $\begin{array}{l}\text { XPS } \\
(C / O)\end{array}$ & $\begin{array}{l}\text { Raman } \\
\left(I_{D} / I_{G}\right)\end{array}$ & $\begin{array}{l}\text { Conductivity } \\
\left(\mathrm{S} \mathrm{m}^{-1}\right)\end{array}$ & $\begin{array}{l}\text { TGA } \\
\text { (significant } \\
\text { mass } \\
\text { loss T) }\end{array}$ & \\
\hline 1 & $2.45 \mathrm{GHz}$ & $1,000 W$ & $1 \mathrm{~min}$ & Air & $\begin{array}{l}\text { hydrazine } \\
\text { hydrate }\end{array}$ & No peak & & 0.12 & & $750^{\circ} \mathrm{C}$ & $\begin{array}{l}\text { Hassan et al., } \\
2009\end{array}$ \\
\hline 2 & $2.45 \mathrm{GHz}$ & $250 W$ & $10 \mathrm{~min}$ & Air & $\begin{array}{l}\text { hydrazine } \\
\text { hydrate }\end{array}$ & $\sim 15^{\circ}$ & 8.1 & & & & Elazab et al., 2015 \\
\hline 3 & $2.45 \mathrm{GHz}$ & $300 W$ & $10 \mathrm{~min}$ & Air & $\begin{array}{l}\text { hydrazine } \\
\text { hydrate }\end{array}$ & & 5.28 & & & & Li et al., 2013 \\
\hline 4 & $2.45 \mathrm{GHz}$ & $1,200 W$ & $2 \min$ & Air & DMSO & $\sim 24^{\circ}$ & & & & & Zedan et al., 2010 \\
\hline 5 & $2.45 \mathrm{GHz}$ & $800 W$ & $10 \min$ & $\mathrm{N}_{2}$ & DMAc & No peak & 5.46 & 0.96 & 200 & $\sim 500^{\circ} \mathrm{C}$ & Chen et al., 2010 \\
\hline 6 & $2.45 \mathrm{GHz}$ & $750 W$ & $2 \min$ & Air & DMF & & & 0.94 & & & Liu et al., 2011 \\
\hline 7 & $2.45 \mathrm{GHz}$ & $100 \mathrm{~W}$ & $30 \mathrm{~min}$ & Air & DMF & $13.4^{\circ}$ & 6.13 & 0.95 & 29.9 & & Zhao et al., 2014 \\
\hline
\end{tabular}

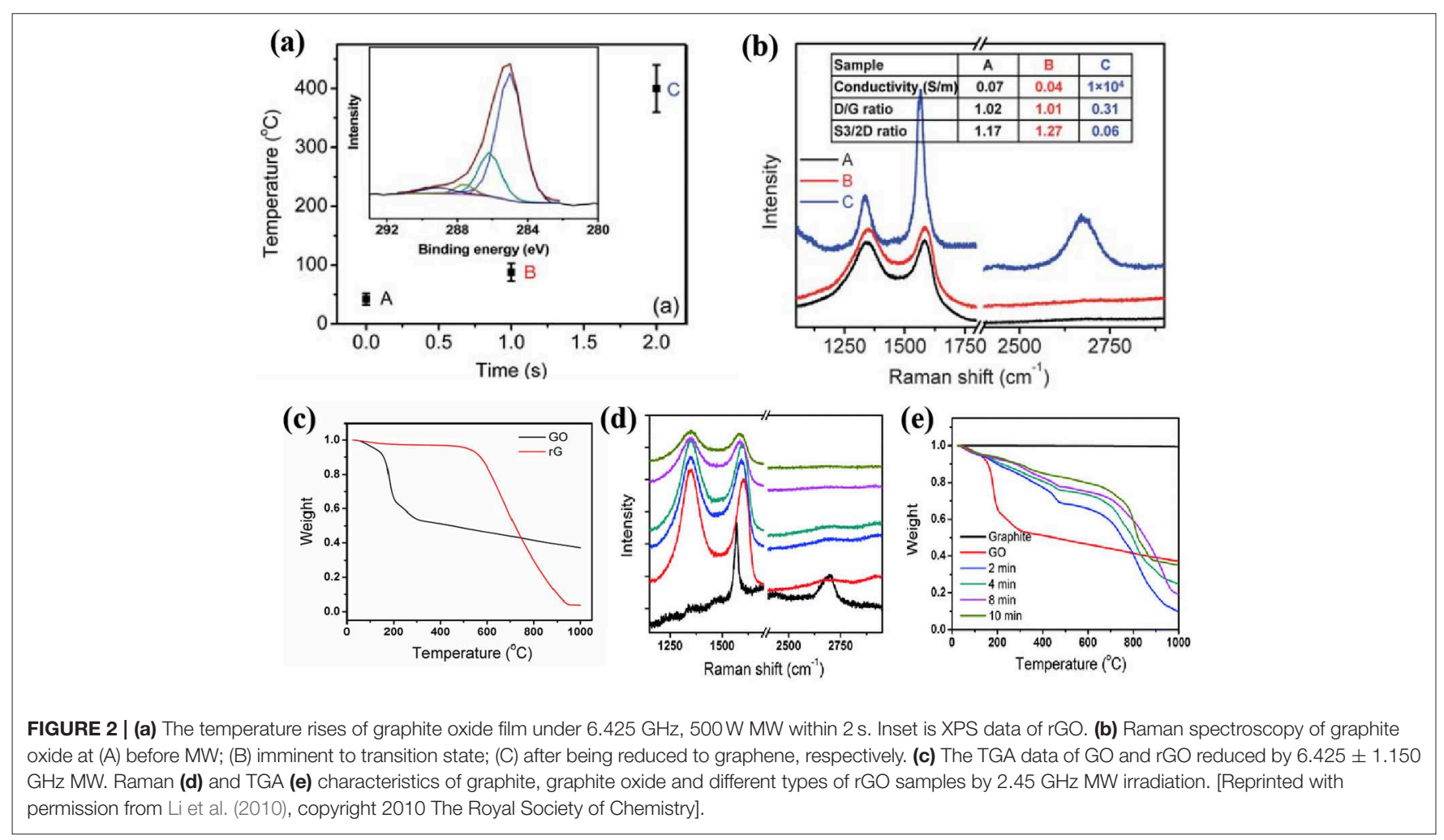

graphene oxide was treated with $\mathrm{CaCl}_{2}$ solution and then washed with DI water, dried in air and pulled out from the filter paper. Finally, a small piece of rGO "paper" obtained by thermal annealing was placed on the as-obtained large graphene oxide paper to act as a trigger, as shown in Figure 4a. After $800 \mathrm{~W}$ microwave irradiation for $2 \mathrm{~s}$ in air, arc discharge process started. The irradiation was maintained for extra 3$5 \mathrm{~s}$ and high-quality microwave reduced graphene oxide paper was obtained. In XPS spectrum, the characteristic peak for C-O vanished, suggesting the significant removal efficiency of oxygencontaining group. Raman spectra of MW-rGO showed sharp G and $2 \mathrm{D}$ bands, and low-intensity $\mathrm{D}$ band. In contrast, the Raman spectra of $\mathrm{rGO}$ derived from conventional thermal reduction at $800^{\circ} \mathrm{C}$ showed a strong $\mathrm{D}$ band and none $2 \mathrm{D}$ band, indicating microwave heating is very beneficial for recovering the highly ordered graphene-like structures which was also confirmed by the conductivity. The sheet resistance of the MW-rGO was measured to be about $40 \Omega \mathrm{cm}^{-2}$, far less than that (about $796 \Omega \mathrm{cm}^{-2}$ ) of $\mathrm{rGO}$ prepared by $800^{\circ} \mathrm{C}$ annealing. They further examined the Raman spectra of graphene-triggered microwave reduction at different positions, and found the part of graphene oxide located nearest to the trigger was not reduced the best, as shown in Figure $\mathbf{4 b}$. Hence, they proposed that the microwave reduction can be not only governed by a simple thermal 

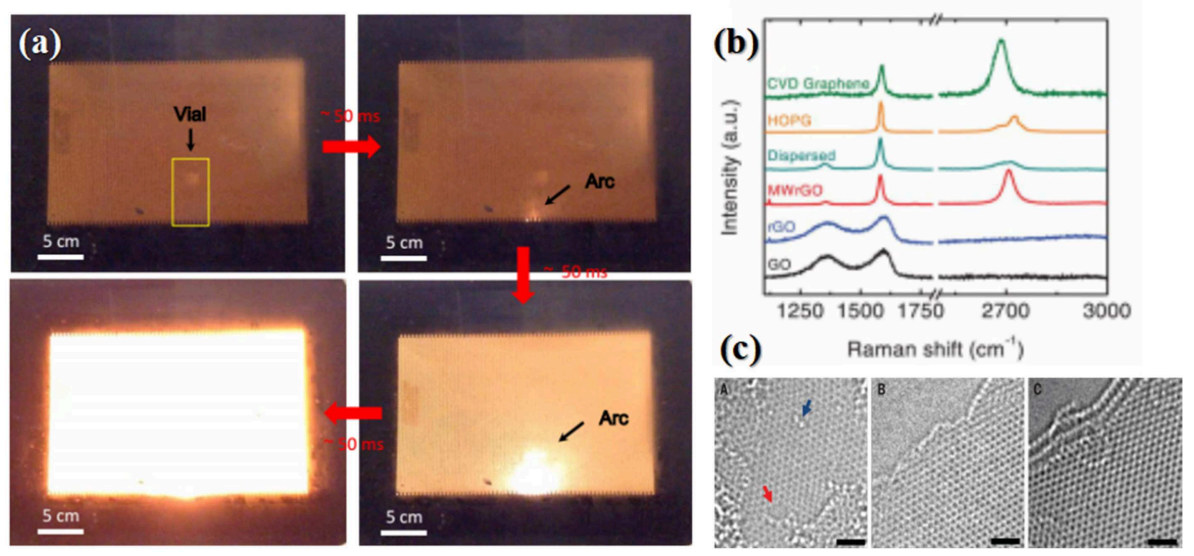

FIGURE 3 | (a) Digital picture showing the formation of arcs during graphene oxide microwaving. (b) Raman spectra of microwave-reduced GO (MW-rGO) and other different rGO samples. (c) HR-TEM of MW-rGO nanosheets. (A) single-layer rGO presenting high density of defects. HR-TEM of (B) Bilayer and (C) trilayer MW-rGO showing highly ordered structure. The red arrow denotes a hole; the blue arrow indicates an oxygen functional group, scale bars, $1 \mathrm{~nm}$. [Reprinted with permission from Voiry et al. (2016), Copyright 2016 American Association for the Advancement of Science].

(a)

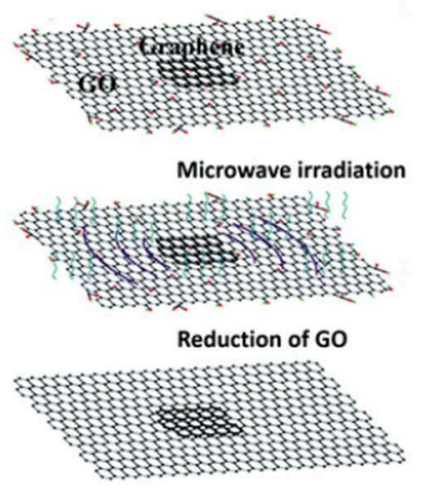

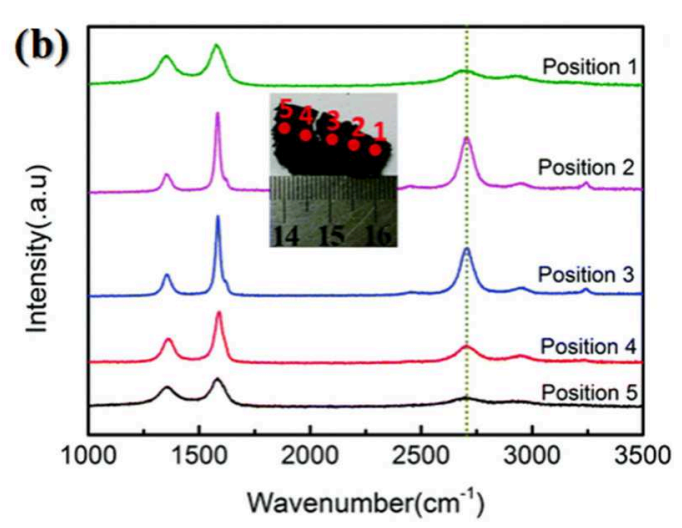

FIGURE 4 | (a) Schematic diagram of the fabrication process of graphene (rGO paper)-triggered microwave reduction. (b) Raman spectra of five measurement points on a strip MW-rGO sample. [Reprinted with permission from Jiang et al. (2018), copyright 2018 The Royal Society of Chemistry].

reduction process but the result of the thermal effect and arc discharge (Jiang et al., 2018).

Instead of putting a small piece of graphene as the trigger, Wan et al. (2018) put a fully bended copper wire inside graphene oxide to absorb $2.45 \mathrm{GHz}$ microwave irradiation intensively and hence trigger immediate arcs and fire to reduce the graphene oxide, as shown in Figures 5a,b. Microwave treatment is applied for $2 \mathrm{~s}$ one time. The decreasing $\mathrm{D}$ band in Raman spectra under different microwave treating times indicate that high crystalline graphene was obtained after microwave treatment.

Low-temperature reduction of graphene oxide is of great importance when graphene oxide film was deposited on glass or plastic substrates. Han et al. (2015) demonstrated microwaveassisted low-temperature thermal reduction of few-layered graphene oxide film. Specifically, they put the graphene oxide film at the center of the highest magnetic field in a single mode microwave reactor which was operated at $2.45 \mathrm{GHz}$ with a power of $42 \mathrm{~W}$ to ensure that the temperature was below $250^{\circ} \mathrm{C}$ during the whole process. After $5 \mathrm{~min}$ treatment in the air, $\mathrm{I}_{\mathrm{D}} / \mathrm{I}_{\mathrm{G}}$ in the Raman spectrum of the product decreased from 2.89 to 1.56 and $\mathrm{C} / \mathrm{O}$ derived from XPS results increased from 7.8 to 17.5. In addition, microwave-enabled exfoliation leading to thinner pieces was also observed in their work.

The characteristics of the as-obtained rGO products derived from different microwave-assisted thermal reduction of graphene oxide methods are summarized and listed in Table 2. Arc discharge caused by microwave irradiation is very beneficial for obtaining high-quality $\mathrm{rGO}$, as evidence by the short reaction time, the low $\mathrm{I}_{\mathrm{D} / \mathrm{I}} \mathrm{I}_{\mathrm{G}}$ values, the high $\mathrm{C} / \mathrm{O}$ values and the conductivity values of most as-derived rGO. It is worth to note that $\mathrm{rGO}$ containing only $4 \%$ oxygen and exhibiting pristine CVD graphene-like features in the Raman spectrum was successfully fabricated via this reducing strategy. Besides, owning to the ultra-rapid treating process, protecting atmosphere is not always necessary. However, too long treatment time would result in re-oxidation and consequently rGO with worse quality when 

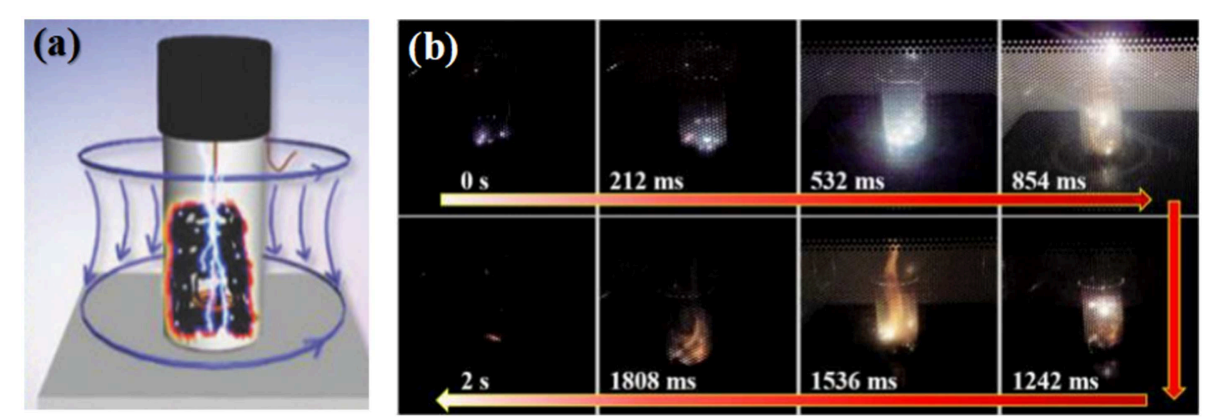

FIGURE 5 | (a) Schematic diagram of the microwave combustion system. (b) Digital picture showing the formation of arcs during microwave process. [Reprinted with permission from Wan et al. (2018), copyright 2018 John Wiley and Sons].

the reduction is done in the air. Since the amounts of GO samples and the microwave heating chambers in different work were different, which would affect the power intensity imposed on the $\mathrm{GO}$, it is also difficult to draw a conclusion regarding the effect of microwave power here.

\section{Microwave-Assisted Simultaneous Exfoliation and Reduction of Graphite Oxide}

Beside of direct reduction of graphene oxide to yield rGO, thermal shock like flash-assisted simultaneous exfoliation and reduction of graphite oxide at temperatures up to $1,050^{\circ} \mathrm{C}$ has also been used. Theoretically, microwave heating which is well-known for its rapid heating feature is very promising in enabling simultaneous exfoliation and reduction of graphite oxide. In 2010, Zhu et al. (2010a) treated graphite oxide powder in microwave oven at $700 \mathrm{~W}$ for $1 \mathrm{~min}$ in ambient atmosphere. Large volume expansion as shown in Figures $\mathbf{6 a}, \mathbf{b}$ accompanied with violent fuming followed by sparking was observed. They found that a minimum power of $280 \mathrm{~W}$ was required to expand the graphite oxide powder successfully, which was probably due to the insulating feature that resulted in inferior microwave absorption ability. After microwave treatment, the as-obtained rGO had a worm-like morphology, in which many regions are wrinkled and folded (Figures $\mathbf{6 c}, \mathbf{d}$ ). XPS results showed that C/O increased from 0.79 to 2.75 (Figure 6e). XRD spectrum showed a broad peak centered at $2 \theta=25^{\circ}$. The conductivity was measured to be about $274 \mathrm{~S} \mathrm{~m}^{-1}$.

Under microwave irradiation, graphite oxide itself might not be heated to a high enough temperature to cause its exfoliation and reduction efficiently due to its inferior microwave absorption ability. Scientists have tried several ways to come over this problem.

Park et al. (2011a) mixed graphite oxide powder with $10 \%$ graphene nanosheets to realized efficient exfoliation and reduction under microwave irradiation. The temperature rising rate was estimated to be $2,000^{\circ} \mathrm{C} / \mathrm{min}$, which was high enough to build up pressure to overcome the van der Waals forces between the graphene sheets in graphite oxide for exfoliation. Huge volume expansion was observed after $10 \mathrm{~s}$, followed by arc after $40 \mathrm{~s}$. SEM images (Figure 7) showed that the prepared rGO also had a worm-like structure composed of
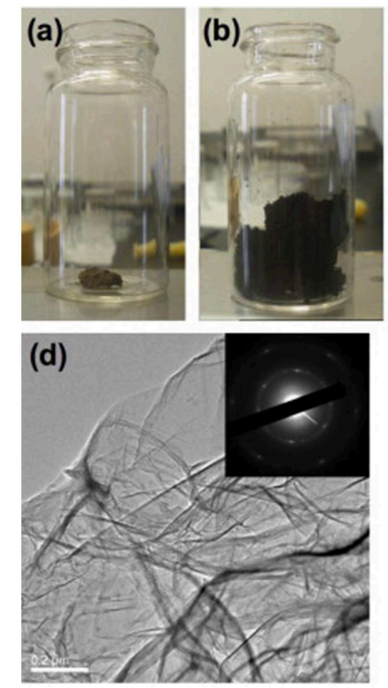

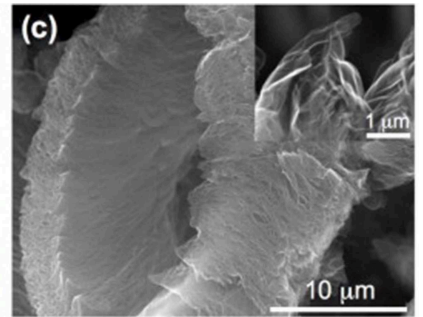

(e)

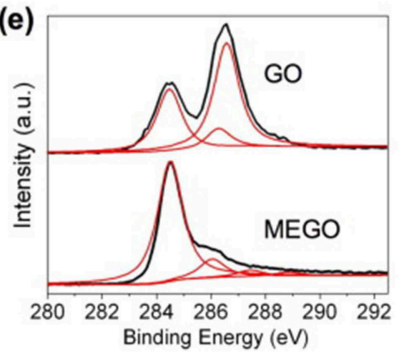

FIGURE 6 | Optical photos of graphite oxide before (a) and after (b) treatment in a microwave oven for $1 \mathrm{~min}$. (c) Typical SEM image of as prepared microwave exfoliated graphite oxide (MEGO) by microwave irradiation with a high magnification SEM image in the inset showing the crumpled MEGO sheets. (d) Typical TEM image of the MEGO and the corresponding electron diffraction pattern. (e) XPS C1s spectra of GO and MEGO. [Reprinted with permission from Zhu et al. (2010a), Copyright 2010 Elsevier].

ultra-thin sheets, which is different from randomly agglomerated and wrinkled sheets prepared from solution-based reduction syntheses. HR-TEM images suggested the presence of single or a few layers of graphene nanosheets as shown in Figure 7. They further compared the effect of reduction atmosphere on the product quality. The $\mathrm{rGO}$ prepared in air, $\mathrm{Ar}, \mathrm{H}_{2}+\mathrm{Ar}$ (1:9) showed a $\mathrm{C} / \mathrm{O}$ ratio of $3.6,11.45,18.5$, respectively and $\mathrm{I}_{\mathrm{D}} / \mathrm{I}_{\mathrm{G}}$ values of $0.853,0.842$, and 0.785 , respectively in Raman spectra, respectively. The rGO prepared in $\mathrm{Ar}, \mathrm{H}_{2}+\mathrm{Ar}$ showed a conductivity of $7.41 \times 10^{2}$ and $1.25 \times 10^{3} \mathrm{~S}$ $\mathrm{m}^{-1}$, respectively. Hydrogen containing atmosphere is the most effective because $\mathrm{H}_{2} \mathrm{O}$ was formed instead of $\mathrm{CO}_{2}$, which prevents the formation of vacancies and defects due to the loss of carbon atoms.

Wen et al. (2014) applied a sequential chemical reduction and microwave exfoliation and reduction of graphite oxide to 
TABLE 2 | Characteristics of rGO products obtained by different microwave-assisted thermal reduction.

\begin{tabular}{|c|c|c|c|c|c|c|c|c|c|c|}
\hline & \multicolumn{4}{|c|}{ Experiment conditions } & \multicolumn{5}{|c|}{ Results } & \multirow[t]{2}{*}{ References } \\
\hline & Frequency & $\begin{array}{l}\text { MW } \\
\text { power }\end{array}$ & $\begin{array}{l}\text { MW } \\
\text { time }\end{array}$ & Atmosphere & $\begin{array}{l}\text { XRD } \\
\text { (peak } \\
\text { location) }\end{array}$ & $\begin{array}{l}\text { XPS } \\
(\mathrm{C} / 0)\end{array}$ & $\begin{array}{l}\text { Raman } \\
\left(\mathrm{I}_{\mathrm{D}} / \mathrm{I}_{\mathrm{G}}\right)\end{array}$ & Conduct & $\begin{array}{l}\text { TGA } \\
\text { (significant } \\
\text { mass loss T) }\end{array}$ & \\
\hline 1 & $2.45 \mathrm{GHz}$ & $42 W$ & $5 \min$ & Air & & 17.5 & 1.56 & $\begin{array}{l}6 \times 10^{3} \\
\Omega \mathrm{cm}^{-2}\end{array}$ & & Han et al., 2015 \\
\hline 2 & $6.425 \mathrm{GHz}$ & $500 W$ & $2 s$ & Air & & & 0.3 & $\begin{array}{l}1 \times 10^{4} \\
\mathrm{Sm}^{-1}\end{array}$ & $668^{\circ} \mathrm{C}$ & Li et al., 2010 \\
\hline \multirow[t]{2}{*}{3} & $2.45 \mathrm{GHz}$ & $800 W$ & $5-7 s$ & Air & $25.6^{\circ}$ & & 0.32 & $\begin{array}{l}40 \Omega \\
\mathrm{cm}^{-2}\end{array}$ & & Jiang et al., 2018 \\
\hline & & & & $\mathrm{N}_{2}$ & & & 0.14 & & & \\
\hline 4 & $2.45 \mathrm{GHz}$ & $1,000 \mathrm{~W}$ & $1-2 s$ & $\mathrm{Ar}$ & & & $<0.1$ & & & Voiry et al., 2016 \\
\hline 5 & $2.45 \mathrm{GHz}$ & $1,000 \mathrm{~W}$ & $8 \mathrm{~min}$ & Air & & & & & $800^{\circ} \mathrm{C}$ & Li et al., 2010 \\
\hline 6 & $2.45 \mathrm{GHz}$ & & $2-40 s$ & Air & No peak & & & & & Wan et al., 2018 \\
\hline
\end{tabular}

TABLE 3 | Characteristics of rGO products derived from different microwave-assisted simultaneous thermal exfoliation and reduction.

\begin{tabular}{|c|c|c|c|c|c|c|c|c|c|c|c|}
\hline & \multicolumn{4}{|c|}{ Experiment conditions } & \multicolumn{5}{|c|}{ Results } & \multirow{2}{*}{$\begin{array}{l}\text { Additional } \\
\text { information }\end{array}$} & \multirow[t]{2}{*}{ References } \\
\hline & Frequency & MW pow & MW time & Atmosphere & $\begin{array}{l}\text { XRD (peak } \\
\text { location) }\end{array}$ & $\begin{array}{l}\text { XPS } \\
(\mathrm{C} / O)\end{array}$ & $\begin{array}{l}\text { Raman } \\
\left(\mathrm{I}_{D} / \mathrm{I}_{G}\right)\end{array}$ & $\begin{array}{l}\text { Conductivity } \\
\left(\mathrm{S} \mathrm{m}^{-1}\right)\end{array}$ & $\begin{array}{l}\text { TGA } \\
\text { (significant } \\
\text { mass loss } \mathrm{T} \text { ) }\end{array}$ & & \\
\hline 1 & $2.45 \mathrm{GHz}$ & $700 W$ & $1 \mathrm{~min}$ & Air & $25^{\circ}$ & 2.75 & & 274 & $\sim 500^{\circ} \mathrm{C}$ & & Zhu et al., 2010a \\
\hline \multirow[t]{3}{*}{2} & $2.45 \mathrm{GHz}$ & $1,600 W$ & $50 s$ & Air & & 3.6 & 0.853 & & & & Park et al., $2011 \mathrm{~b}$ \\
\hline & & & & $\mathrm{Ar}$ & & 11.45 & 0.842 & $7.41 \times 10^{2}$ & & & \\
\hline & & & & $\mathrm{Ar}+\mathrm{H}_{2}$ & & 18.5 & 0.785 & $1.25 \times 10^{3}$ & & & \\
\hline \multirow[t]{2}{*}{3} & $5.8 \mathrm{GHz}$ & $1,400 W$ & $10 \min$ & $\mathrm{N}_{2}$ & & 7.24 & $\sim 0.7$ & $7.63 \times 10^{2}$ & & & Wen et al., 2014 \\
\hline & & & & & & 10.33 & $\sim 1.07$ & $1.19 \times 10^{4}$ & & $\begin{array}{l}\text { Pretreated by } \\
\mathrm{NaBH}_{4} \text {, and } \\
\text { Raman } \\
\text { beacomes } \\
\text { worse. Maybe } \\
\text { the } \mathrm{MW} \text { not be } \\
\text { sufficient to } \\
\text { repair the large } \\
\text { amount of } \\
\text { defects caused } \\
\text { by } \mathrm{NaBH}_{4}\end{array}$ & \\
\hline \multirow[t]{3}{*}{4} & $2.45 \mathrm{GHz}$ & $1,000 \mathrm{~W}$ & $1 \mathrm{~min}$ & $\mathrm{~N}_{2}$ & $\sim 12 \& 24^{\circ}$ & 2.42 & & & $\sim 450^{\circ} \mathrm{C}$ & & Pokharel et al., 2014 \\
\hline & & & $2 \min$ & & $\sim 22^{\circ}$ & 5.78 & & & & & \\
\hline & & & $3 \min$ & & $26.3^{\circ}$ & 10.39 & & & & & \\
\hline
\end{tabular}

produce rGO. Specifically, graphite oxide powder was treated by $\mathrm{NaBH}_{4}$ at $95^{\circ} \mathrm{C}$ for $2 \mathrm{~h}$, and subsequently made into a film, which was microwave irradiated at $5.8 \mathrm{GHz}$ with a power of $1,400 \mathrm{~W}$ for $10 \mathrm{~min}$ in $\mathrm{N}_{2}$. After $\mathrm{NaBH}_{4}$ treatment, a $\mathrm{C} / \mathrm{O}$ value of 3.84 , an $\mathrm{I}_{\mathrm{D}} / \mathrm{I}_{\mathrm{G}}$ value of 1.05 in Raman, and a conductivity of $1.41 \times 10^{2} \mathrm{~S} \mathrm{~m}^{-1}$ were obtained. During the microwave treatment, the sample expanded to a loose floc and transmitted bright orange light, leading to ultrathin sheets with a $\mathrm{C} / \mathrm{O}$ ratio of 10.33 , an $\mathrm{I}_{\mathrm{D}} / \mathrm{I}_{\mathrm{G}}$ ratio of 1.07 in the Raman spectrum and a conductivity of $1.19 \times 10^{4} \mathrm{~S} \mathrm{~m}^{-1}$. Sole microwave irradiation at $5.8 \mathrm{GHz}$ with a power of $1,400 \mathrm{~W}$ for $10 \mathrm{~min}$ without a preceding chemical reduction process gave yield to a $\mathrm{C} / \mathrm{O}$ of 7.24 and an $\mathrm{I}_{\mathrm{D}} / \mathrm{I}_{\mathrm{G}}$ of 0.89 in Raman spectrum. This demonstrated that solid-state microwave irradiation not only removed oxygen-containing groups, but also repaired defects on the graphene sheets while $\mathrm{NaBH}_{4}$ though effective for removing oxygen-containing groups may induce more defects. Further, through XPS analysis of content of $\mathrm{C}-\mathrm{O}$ and $\mathrm{C}=\mathrm{O}$ groups, they found that microwave irradiation removed $\mathrm{C}=\mathrm{O}$ more readily than $\mathrm{C}-\mathrm{O}$ while the chemical reduction method removed $\mathrm{C}-\mathrm{O}$ more efficiently.

Pokharel et al. (2014) developed a multi-step reduction technique to obtain rGO from graphite oxide. In the first step, graphite oxide with a $\mathrm{C} / \mathrm{O}$ of 0.83 was exfoliated within $1 \mathrm{~min}$ under microwave irradiation at $2.45 \mathrm{GHz}$ with a power of $1,000 \mathrm{~W}$ in $\mathrm{N}_{2}$ without becoming red. The expanded graphite 

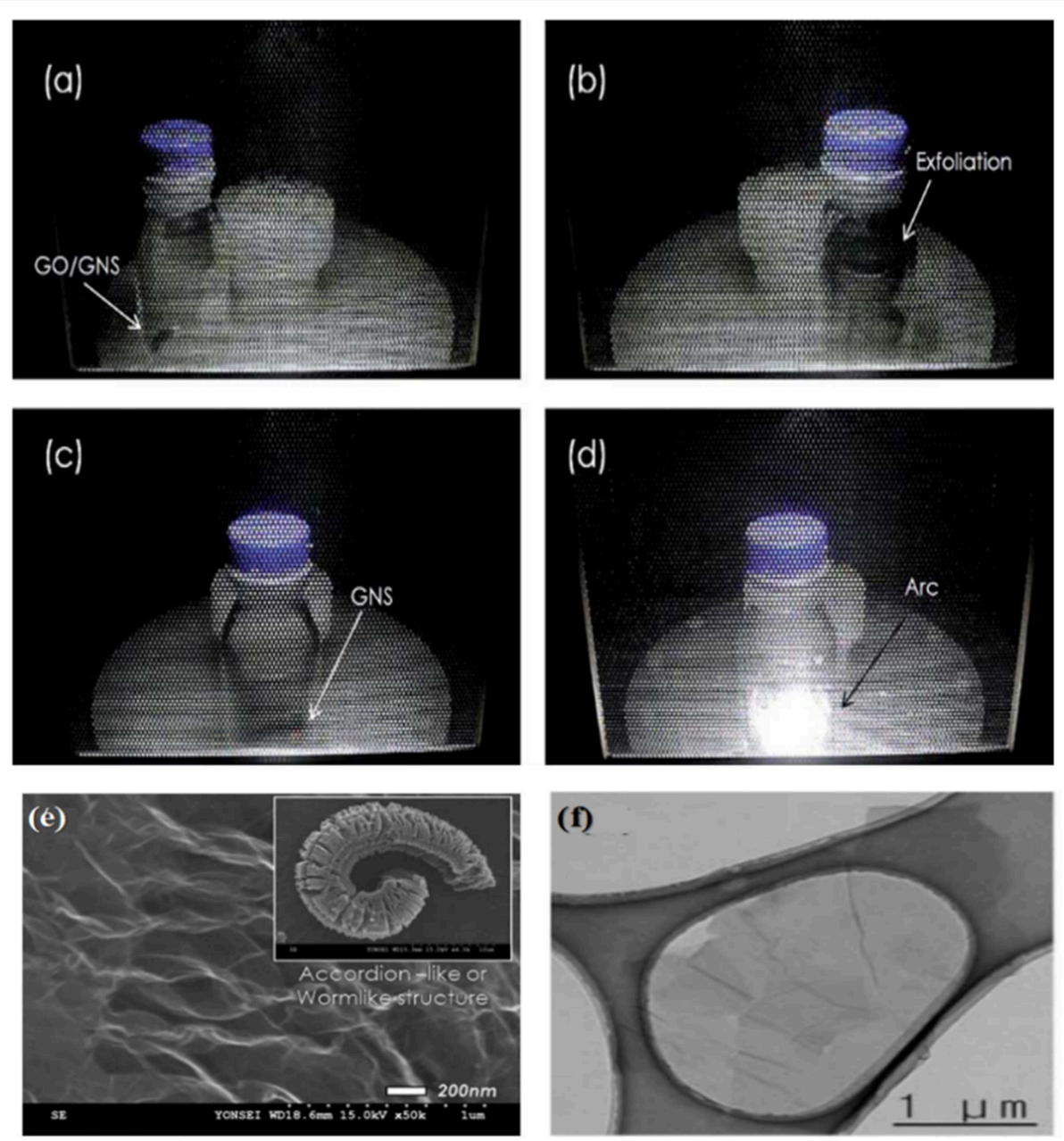

FIGURE 7 | Digital images of the sequence of the exfoliation process during solid-state microwave irradiation synthesis: (a) graphite oxide/graphene nanosheets (GNS) mixture powder, (b) exfoliation of graphite oxide/GNS powder. (c) GNS after exfoliation and (d) arc evolution from GNS. (e) SEM images of GNS by solid-state microwave irradiation synthesis. (f) HR-TEM images of GNS. [Reprinted with permission from Park et al. (2011a), copyright 2011 The Royal Society of Chemistry].

oxide had a $\mathrm{C} / \mathrm{O}$ of 2.42. However, it was so loose that microwave could not concentrate on a definite area for further reduction of graphite oxide. Hence, in the second step, the expanded graphite oxide was collected and then exposed to additional microwave irradiation for 1 and $2 \mathrm{~min}$, resulting in $\mathrm{rGO}$ showing a $\mathrm{C} / \mathrm{O}$ ratio of 5.78 and 10.39 , respectively.

The characteristics of the as-obtained rGO products derived from different microwave-assisted simultaneous thermal exfoliation and reduction of graphite oxide methods are summarized and listed in Table 3. As can be seen from the $\mathrm{C} / \mathrm{O}$ values, $\mathrm{I}_{\mathrm{D}} / \mathrm{I}_{\mathrm{G}}$ values, mass loss temperatures and conductivities, simultaneous exfoliation and reduction was not able to yield rGO with as high quality as those obtained from thermal reduction of graphene oxides. However, when combined with reducing atmosphere (i.e., $\mathrm{H}_{2}$ ) or pretreatment with strong reducing reagents $\left(\mathrm{NaBH}_{4}\right)$, the reduction degree could be greatly enhanced.

\section{PERSPECTIVES}

It is expected that the explored methods for microwave-assisted reduction of graphene/graphite oxide into high-quality rGO could be extended to fabrication of graphene composites. The microwave-induced arc facilitated short reaction time at high temperature is not only beneficial for getting high-quality rGO, but also promising in facilitating the formation of highquality nanomaterials (such as metal nanocrystals, metal oxides nanocrystals, and so on) with advanced performance. In addition, the methods could be extended to fabrication of other conductive materials that could trigger sparks under microwave irradiation, like graphene does.

\section{AUTHOR CONTRIBUTIONS}

All authors listed have made a substantial, direct and intellectual contribution to the work, and approved it for publication. 


\section{FUNDING}

This work was financially supported by the National Natural Science Foundation of China (Grant No.
61801314), National Natural Science Foundation of China (Grant No. 61731013), Fundamental Research Funds for the Central Universities of China (Grant No. YJ201703).

\section{REFERENCES}

Akhavan, O. (2015). Bacteriorhodopsin as a superior substitute for hydrazine in chemical reduction of single-layer graphene oxide sheets. Carbon 81, 158-166. doi: 10.1016/j.carbon.2014.09.044

Bak, S., Kim, D., and Lee, H. (2016). Graphene quantum dots and their possible energy applications: a review. Curr. Appl. Phys. 16, 1192-1201. doi: 10.1016/j.cap.2016.03.026

Bastiurea, M., Rodeanu, M. S., Dima, D., Murarescu, M., and Andrei, G. (2015). Thermal and mechanical properties of polyester composites with graphene oxide and graphite. Dig. J. Nanomater. Biostruct. 10, 521-533.

Basu, R., Kinnamon, D., and Garvey, A. (2016). Graphene and liquid crystal mediated interactions. Liq. Cryst. 43, 2375-2390. doi: 10.1080/02678292.2016.1197429

Bi, H., Xie, X., Yin, K., Zhou, Y., Wan, S., He, L., et al. (2012). Hierarchical nanocomposites derived from nanocarbons and layered double hydroxidesproperties, synthesis, and applications. Adv. Funct. Mater. 22, 4421-4425. doi: 10.1002/adfm.201102222

Cao, M.-S., Wang, X.-X., Cao, W.-Q., and Yuan, J. (2015). Ultrathin graphene: electrical properties and highly efficient electromagnetic interference shielding. J. Mater. Chem. C 3, 6589-6599. doi: 10.1039/c5tc01354b

Chabot, V., Higgins, D., Yu, A., Xiao, X., Chen, Z., and Zhang, J. (2014). A review of graphene and graphene oxide sponge: material synthesis and applications to energy and the environment. Energ. Environ. Sci. 7, 1564-1596. doi: $10.1039 / \mathrm{c} 3 \mathrm{ee} 43385 \mathrm{~d}$

Chatterjee, S. G., Chatterjee, S., Ray, A. K., and Chakraborty, A. K. (2015). Graphene-metal oxide nanohybrids for toxic gas sensor: a review. Sensors Actuat. B Chem. 221, 1170-1181. doi: 10.1016/j.snb.2015.07.070

Chen, W., and Yan, L. (2010). Preparation of graphene by a low-temperature thermal reduction at atmosphere pressure. Nanoscale 2, 559-563. doi: 10.1039/b9nr00191c

Chen, W., Yan, L., and Bangal, P. R. (2010). Preparation of graphene by the rapid and mild thermal reduction of graphene oxide induced by microwaves. Carbon 48, 1146-1152. doi: 10.1016/j.carbon.2009.11.037

Das, T. K., and Prusty, S. (2013). Graphene-based polymer composites and their applications. Polym. Plast. Technol. 52, 319-331. doi: 10.1080/03602559.2012.751410

Dreyer, D. R., Park, S., Bielawski, C. W., and Ruoff, R. S. (2010). The chemistry of graphene oxide. Chem. Soc. Rev. 39, 228-240. doi: 10.1039/B917103G

Elazab, H. A., Siamaki, A. R., Moussa, S., Gupton, B. F., and Elshall, M. S. (2015). Highly efficient and magnetically recyclable graphene-supported $\mathrm{Pd} / \mathrm{Fe}_{3} \mathrm{O}_{4}$ nanoparticle catalysts for suzuki and heck cross-coupling reactions. Appl. Catal. A Gen. 491, 58-69. doi: 10.1016/j.apcata.2014.11.033

Eswaraiah, V., Sankaranarayanan, V., and Ramaprabhu, S. (2011). Functionalized graphene-PVDF foam composites for EMI shielding Macromol. Mater. Eng. 296, 894-898. doi: 10.1002/mame.201100035

Gannavarapu, K. P., Azizighannad, S., Muthukumar, S., Mitra, S., and Dandamudi, R. B. (2018). Microwave-assisted biogenic synthesis of metal-decorated reduced graphene oxide and their electrochemical properties. ChemistrySelect 3, 13438-13441. doi: 10.1002/slct.201803420

Gao, X., Jang, J., and Nagase, S. (2010). Hydrazine and thermal reduction of graphene oxide: reaction mechanisms, product structures, and reaction design. J. Phys. Chem. C 114, 832-842. doi: 10.1021/jp909284g

Han, H. J., Chen, Y. N., and Wang, Z. J. (2015). Effect of microwave irradiation on reduction of graphene oxide films. Rsc Adv. 5, 92940-92946. doi: $10.1039 / \mathrm{c} 5 \mathrm{ra} 19268 \mathrm{~d}$

Han, Q., Chen, N., Zhang, J., and Qu, L. (2017). Graphene/graphitic carbon nitride hybrids for catalysis. Mater. Horiz. 4, 832-850. doi: 10.1039/c7mh00379j

Hassan, H. M. A., Abdelsayed, V., Khder, A. E. R. S., Abouzeid, K. M., Terner, J., El-Shall, M. S., et al. (2009). Microwave synthesis of graphene sheets supporting metal nanocrystals in aqueous and organic media. J. Mater. Chem. 19, 3832-3837. doi: 10.1039/B906253J

$\mathrm{Hu}$, M., Yao, Z., and Wang, X. (2017). Graphene-based nanomaterials for catalysis. Ind. Eng. Chem. Res. 56, 3477-3502. doi: 10.1021/acs.iecr.6b05048

Hur, S. H., and Park, J.-N. (2013). Graphene and its application in fuel cell catalysis: a review. Asia Pac. J. Chen. Eng. 8, 218-233. doi: 10.1002/apj.1676

Jiang, W. S., Yang, C., Chen, G. X., Yan, X. Q., Chen, S. N., Su, B. W., et al. (2018). Preparation of high-quality graphene using triggered microwave reduction under an air atmosphere. J. Mater. Chem. C 6, 1829-1835. doi: 10.1039/C7TC03957C

Jones, D. A., Lelyveld, T. P., Mavrofidis, S. D., Kingman, S. W., and Miles, N. J. (2002). Microwave heating applications in enviromnental engineering-a review. Resour. Conserv. Recy. 34, 75-90. doi: 10.1016/s0921-3449(01)00088-x

Kappe, C. O. (2004). Controlled microwave heating in modern organic synthesis. Angew. Chem. Int. Edit. 43, 6250-6284. doi: 10.1002/anie.200400655

Katkov, V. L., and Osipov, V. A. (2017). Journal of vacuum science \& technology. J. Vac. Sci. Technol. B 2017, 35. doi: 10.1116/1.4995380

Kaur, M., Kaur, M., and Sharma, V. K. (2018). Nitrogen-doped graphene and graphene quantum dots: a review onsynthesis and applications in energy, sensors and environment. Adv. Colloid Interfac. 59, 44-64. doi: 10.1016/j.cis.2018.07.001

Kumar, D., Raghavan, C. M., Sridhar, C., Shin, J. H., Ryu, S. H., Jang, K., et al. (2015). Microwave-assisted synthesis, characterization of reduced graphene oxide, and its antibacterial activity. B. Korean Chem. Soc. 36, 2034-2038. doi: 10.1002/bkcs.10394

Le, L. T., Ervin, M. H., Qiu, H., Fuchs, B. E., and Lee, W. Y. (2011). Graphene supercapacitor electrodes fabricated by inkjet printing and thermal reduction of graphene oxide. Electrochem. Commun. 13, 355-358. doi: 10.1016/j.elecom.2011.01.023

Li, J., and Wu, N. (2015). Graphene-supported metal/metal oxide nanohybrids: synthesis and applications in heterogeneous catalysis. Catal. Sci. Technol. 5, 1360-1384. doi: 10.1002/chin.201537235

Li, J., Yang, Z., Qiu, H., Dai, Y., Zheng, Q., Zheng, G.-P., et al. (2013). Microwaveassisted simultaneous reduction and titanate treatment of graphene oxide. $J$. Mater. Chem. A 1, 11451-11456. doi: 10.1039/C3TA12228J

Li, X., Rui, M., Song, J., Shen, Z., and Zeng, H. (2015). Carbon and graphene quantum dots for optoelectronic and energy devices: a review. Adv. Funct. Mater. 25, 4929-4947. doi: 10.1002/adfm.201501250

Li, Z., Yao, Y., Lin, Z., Moon, K. S., Lin, W., and Wong, C. (2010). Ultrafast, dry microwave synthesis of graphene sheets. J. Mater. Chem. 20, 4781-4783. doi: 10.1039/c0jm00168f

Li,Y., Li, T., Yao, M., and Liu, S. (2012). Metal-free nitrogen-doped hollow carbon spheres synthesized by thermal treatment of poly(o-phenylenediamine) for oxygen reduction reaction in direct methanol fuel cell applications. J. Mater. Chem. 22, 10911-10917. doi: 10.1039/c2jm30781b

Lin, F., Tong, X., Wang, Y., Bao, J., and Wang, Z. M. (2015). Graphene oxide liquid crystals: synthesis, phase transition, rheological property, and applications in optoelectronics and display. Nanoscale Res. Lett. 10:435. doi: 10.1186/s11671-015-1139-1

Lin, Z., Yao, Y., Li, Z., Liu, Y., Li, Z., and Wong, C. P. (2010). Solvent-assisted thermal reduction of graphite oxide. J. Phys. Chem. C 114, 14819-14825. doi: $10.1021 /$ jp 1049843

Liu, S., Tian, J., Wang, L., and Sun, X. (2011). Microwave-assisted rapid synthesis of ag nanoparticles/graphene nanosheet composites and their application for hydrogen peroxide detection. J. Nanopart. Res. 13, 4539-4548. doi: 10.1007/s11051-011-0410-3

Liu, Y., Yuan, L., Yang, M., Zheng, Y., Li, L., Gao, L., et al. (2014). Giant enhancement in vertical conductivity of stacked CVD graphene sheets by self-assembled molecular layers. Nat. Commun. 2014, 5. doi: 10.1038/ ncomms6461 
Mattevi, C., Kim, H., and Chhowalla, M. (2011). A review of chemical vapour deposition of graphene on copper. J. Mater. Chem. 21, 3324-3334. doi: $10.1039 / \mathrm{c} 0 \mathrm{jm} 02126 \mathrm{a}$

Narayan, R., Kim, J. E., Kim, J. Y., Lee, K. E., and Kim, S. O. (2016). Graphene oxide liquid crystals: discovery, evolution and applications. Adv. Mater. 28, 3045-3068. doi: 10.1002/adma.201505122

Novoselov, K. S., Jiang, D., Schedin, F., Booth, T. J., Khotkevich, V. V., Morozov, S. V., et al. (2005). Two-dimensional atomic crystals. Proc. Natl. Acad. Sci. U.S.A. 102, 10451-10453. doi: 10.1073/pnas.0502848102

Park, S., An, J., Potts, J. R., Velamakanni, A., Murali, S., and Ruoff, R. S. (2011b). Hydrazine-reduction of graphite- and graphene oxide. Carbon 49, 3019-3023. doi: 10.1016/j.carbon.2011.02.071

Park, S. H., Bak, S. M., Kim, K. H., Jegal, J. P., Lee, S. I., Lee, J., et al. (2011a). Solid-state microwave irradiation synthesis of high quality graphene nanosheets under hydrogen containing atmosphere. J. Mater. Chem. 21, 680-686. doi: 10.1039/c0jm01007c

Pokharel, P., Truong, Q. T., and Lee, D. S. (2014). Multi-step microwave reduction of graphite oxide and its use in the formation of electrically conductive graphene/epoxy composites. Compos. Part B Eng. 64, 187-193. doi: 10.1016/j.compositesb.2014.04.013

Qin, F., and Brosseau, C. (2012). A review and analysis of microwave absorption in polymer composites filled with carbonaceous particles. J. Appl. Phys. 111, 61301-61301. doi: 10.1063/1.3688435

Schwenke, A. M., Hoeppener, S., and Schubert, U. S. (2015). Synthesis and modification of carbon nanomaterials utilizing microwave heating. Adv. Mater. 27, 4113-4141. doi: 10.1002/adma.201500472

Shao, Y., Wang, J., Wu, H., Liu, J., Aksay, I. A., and Lin, Y. (2010). Graphene based electrochemical sensors and biosensors: a review. Electroanalysis 22, 1027-1036. doi: 10.1002/elan.200900571

Song, W.-L., Cao, M.-S., Lu, M.-M., Bi, S., Wang, C.-Y., Liu, J., et al. (2014). Flexible graphene/polymer composite films in sandwich structures for effective electromagnetic interference shielding. Carbon 66, 67-76. doi: 10.1016/j.carbon.2013.08.043

Stankovich, S., Dikin, D. A., Piner, R. D., Kohlhaas, K. A., Kleinhammes, A., Jia, Y., et al. (2007). Synthesis of graphene-based nanosheets via chemical reduction of exfoliated graphite oxide. Carbon 45, 1558-1565. doi: 10.1016/j.carbon.2007.02.034

Stobinski, L., Lesiak, B., Malolepszy, A., Mazurkiewicz, M., Mierzwa, B., Zemek, J., et al. (2014). Graphene oxide and reduced graphene oxide studied by the XRD, TEM and electron spectroscopy methods. J. Electron Spectrosc. 195, 145-154. doi: 10.1016/j.elspec.2014.07.003

Strankowski, M., Wlodarczyk, D., Piszczyk, A., and Strankowska, J. (2016). Polyurethane nanocomposites containing reduced graphene oxide, FTIR, Raman, and XRD studies. J. Spectrosc. doi: 10.1155/2016/7520741

Thomassin, J.-M., Jerome, C., Pardoen, T., Bailly, C., Huynen, I., and Detrembleur, C. (2013). Polymer/carbon based composites as electromagnetic interference (EMI) shielding materials. Mat. Sci. Eng. R. 74, 211-232. doi: 10.1016/j.mser.2013.06.001

Thostenson, E. T., and Chou, T. W. (1999). Microwave processing: fundamentals and applications. Compos. Part A Appl. Sci. Manufact. 30, 1055-1071. doi: 10.1016/s1359-835x(99)00020-2

Tompsett, G. A., Conner, W. C., and Yngvesson, K. S. (2006). Microwave synthesis of nanoporous materials. ChemPhysChem 7, 296-319. doi: $10.1002 /$ cphc. 200500449
Voiry, D., Yang, J., Kupferberg, J., Fullon, R., Lee, C., Jeong, H. Y., et al. (2016). High-quality graphene via microwave reduction of solution-exfoliated graphene oxide. Science 353, 1413-1416. doi: 10.1126/science.aah3398

Wan, J., Huang, L., Wu, J., Xiong, L., Hu, Z., Yu, H., et al. (2018). Microwave combustion for rapidly synthesizing pore-size-controllable porous graphene. Adv. Funct. Mater. 28:382. doi: 10.1002/adfm.2018 00382

Wang, K., Feng, T., Qian, M., Ding, H., Chen, Y., and Sun, Z. (2011). The field emission of vacuum filtered graphene films reduced by microwave. Appl. Surf. Sci. 257, 5808-5812. doi: 10.1016/j.apsusc.2011.01.109

Wang, Q., and Arash, B. (2014). A review on applications of carbon nanotubes and graphenes as nano-resonator sensors. Comp. Mater. Sci. 82, 350-360. doi: 10.1016/j.commatsci.2013.10.010

Wen, C., Zhao, N., Zhang, D. W., Wu, D., Zhang, Z.-B., and Zhang, S.-L. (2014). Efficient reduction and exfoliation of graphite oxide by sequential chemical reduction and microwave irradiation. Synthetic Met. 194, 71-76. doi: 10.1016/j.synthmet.2014.04.023

Xiao, L., Liao, L., and Liu, L. (2013). Chemical modification of graphene oxide with carbethoxycarbene under microwave irradiation. Chem. Phys. Lett. 556, 376-379. doi: 10.1016/j.cplett.2012.11.084

Zedan, A. F., Sappal, S., Moussa, S., and El-Shall, M. S. (2010). Ligand-controlled microwave synthesis of cubic and hexagonal cdse nanocrystals supported on graphene photoluminescence quenching by graphene. J. Phys. Chem. C 114, 19920-19927. doi: 10.1021/jp107297x

Zhang, H. B., Wang, J. W., Yan, Q., Zheng, W. G., Chen, C., and Yu, Z. Z. (2011). Vacuum-assisted synthesis of graphene from thermal exfoliation and reduction of graphite oxide. J. Mater. Chem. 21, 5392-5397. doi: 10.1039/C1JM $10099 \mathrm{H}$

Zhang, Y., Zhang, L., and Zhou, C. (2013). Review of chemical vapor deposition of graphene and related applications. Accounts Chem. Res. 46, 2329-2339. doi: 10.1021/ar300203n

Zhao, N., Wen, C. Y., Zhang, D. W., Wu, D. P., Zhang, Z. B., and Zhang, S. L. (2014). Liquid-phase and solid-phase microwave irradiations for reduction of graphite oxide. Chinese Phys. B 23:128101. doi: 10.1088/1674-1056/23/12/128101

Zhu, Y., Murali, S., Stoller, M. D., Velamakanni, A., Piner, R. D., and Ruoff, R. S. (2010a). Microwave assisted exfoliation and reduction of graphite oxide for ultracapacitors. Carbon 48, 2118-2122. doi: 10.1016/j.carbon.2010. 02.001

Zhu, Y., Stoller, M. D., Cai, W., Velamakanni, A., Piner, R. D., Chen, D., et al. (2010b). Exfoliation of graphite oxide in propylene carbonate and thermal reduction of the resulting graphene oxide platelets. Acs Nano 4, 1227-1233. doi: $10.1021 / \mathrm{nn} 901689 \mathrm{k}$

Conflict of Interest Statement: The authors declare that the research was conducted in the absence of any commercial or financial relationships that could be construed as a potential conflict of interest.

Copyright (C) 2019 Xie, Zhou and Huang. This is an open-access article distributed under the terms of the Creative Commons Attribution License (CC BY). The use, distribution or reproduction in other forums is permitted, provided the original author(s) and the copyright owner(s) are credited and that the original publication in this journal is cited, in accordance with accepted academic practice. No use, distribution or reproduction is permitted which does not comply with these terms. 